\title{
RENAL LIPOSARCOMA
}

\author{
DIOGO A.L. BADER, LUIS A.B. PERES, SÉRGIO L. BADER
}

West Paraná State University, UNIOESTE, Cascavel, Paraná, Brazil

\begin{abstract}
Introduction: Liposarcoma is a malignant mesenchymal tumor frequently located in retroperitoneum, and rarely presenting an isolated lesion in kidney.

Case Report: Female, Caucasian, 49-year old patient, with family history of renal polycystic disease, was selected for organ donation. During preoperative examinations a renal pleomorphic liposarcoma was detected. She was treated with radical nephrectomy and remains asymptomatic, without evidences of recurrence in control ecographic examinations after a 4-year follow-up.

Comments: Renal liposarcoma is a rare tumor. We report one case incidentally diagnosed during a routine pre-transplantation assessment in renal donor.
\end{abstract}

Key words: kidney; kidney neoplasms; liposarcoma

Int Braz J Urol. 2004; 30: 214-5

\section{INTRODUCTION}

Liposarcoma is a malignant mesenchymal tumor frequently located in the retroperitoneum (1). Isolated lesion in kidney has rarely been described (2). We present a case of renal liposarcoma incidentally diagnosed during the assessment of a candidate to renal donation for transplantation.

\section{CASE REPORT}

Female, Caucasian, 49-year old patient, with family history of renal polycystic disease, was selected for organ donation. During preoperative examination a rounded, heterogeneous, well-defined mass with solid aspect was detected by renal ultrasonography, adjacent to the lower pole of the left kidney. A computerized tomography was performed, showing an expansive, solid, heterogeneous lesion with -38 UH attenuation, poorly defined in the lower third's external edge, measuring $3.8 \times 3.8 \mathrm{~cm}$ and with preservation of perirenal fat. There was no contrast medium impregnation in the tumoral lesion during the late phase (Figure-1). The angiography showed a hypovascularized and hypodense mass. The intravenous urography was normal. Radical nephrectomy was performed following the intraoperative freezing diagnosis of malignant lesion. The pathological examination revealed a brownish nodular structure with $4.8 \mathrm{~cm}$ in diameter, and the microscopy detected neoplastic tissue of mesenchymal origin, spindle and oval cells with abundant cytoplasm, hyperchromic nuclei and intense pleomorphism (Figure-2), characteristic of a renal pleomorphic liposarcoma. The patient has been followed up for 4 years and remains asymptomatic, without evidence of recurrence on control ecographic examinations.

\section{COMMENTS}

Renal liposarcoma is a rare tumor. There are few well-documented reports in the literature, many of those are associated with tuberous sclerosis and probably correspond to angiomyolipomas. The majority of published cases refer to well-differentiated tumors, with dimensions greater than $5 \times 5 \times 4 \mathrm{~cm}$ 


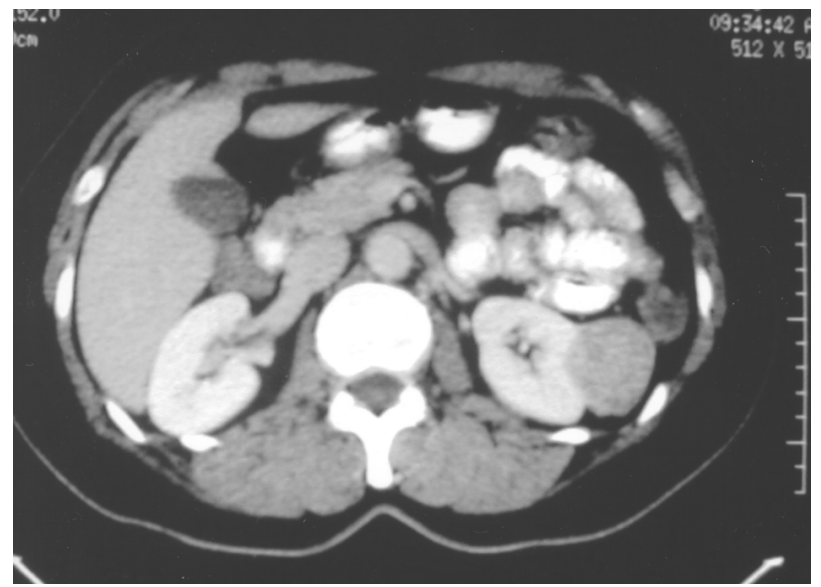

Figure 1 - The computerized tomography shows an expansive, solid, heterogeneous lesion with -38 UH attenuation, poorly defined, in the external edge of the left kidney's lower third, measuring $3.8 \times 3.8 \mathrm{~cm}$ and with preservation of perirenal fat.

and presenting symptoms such as pain, hematuria, abdominal mass or loss of weight. The liposarcoma is classified according to the histological type, in welldifferentiated, myxoid and pleomorphic. The myxoid type occurs in $60 \%$, the well-differentiated in $25 \%$ and the pleomorphic in $10 \%$ of the cases. The pleomorphic type is highly aggressive with high rates of metastases (2). We describe an incidentaloma of the pleomorphic type with $4.8 \mathrm{~cm}$ in diameter.

Perirenal localization is often observed in such tumors, which can mimic renal cystic tumor. The differential diagnosis must include renal cell carcinoma or atypical angiomyolipoma. Some features in the computerized tomography, such as linear vascularization, aneurismal dilatation, hematoma and presence of tissue with fat attenuation speak for angiomyolipoma. Frequently the definitive diagnosis is achieved only through the pathologic examination (3).

The prognosis of liposarcomas depends on the degree of differentiation, size, histological type and tumor staging. The total surgical resection with free margins offers a good probability of cure (2). The standard treatment has been radical nephrectomy, associated or not with radiotherapy. Clinical followup is important to monitor tumor recurrence. There is a report of recurrence 13 years after the initial surgery (2). The case we described here was treated with

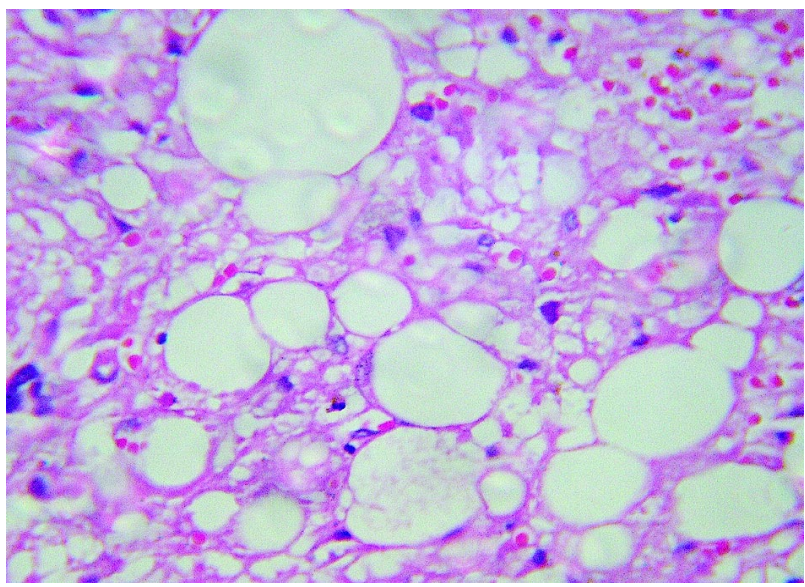

Figure 2 - Histopathological study demonstrating renal pleomorphic liposarcoma. Neoplastic tissue of mesenchymal origin, spindle and oval cells with abundant cytoplasm, hyperchromic nuclei and intense pleomorphism (HE, X40).

radical nephrectomy, presenting a 4-year follow-up, without evidence of recurrence to this moment.

\section{Dr. José R. L. Ferreira and Dr. Alexandre Galvão Bueno assisted in preparing the images and the histological material.}

\section{REFERENCES}

1. Lopes RI, Lopes RN, Filho B: Giant retroperitoneal liposarcoma. Int Braz J Urol. 2002; 28: 227-9.

2. Mayes DC, Fechner RE, Gillenwater JY: Liposarcoma renal. Amer J Surg Pathol. 1990; 14: 268-73.

3. Wang LJ, Wong YC, Chen CJ, See LC: Computerized tomography characteristics that differentiate angiomyolipomas from liposarcomas in the perinephric space. J Urol. 2002; 167: 490-3.

\author{
Received: September 29, 2003 \\ Accepted after revision: January 21, 2004
}

\section{Correspondence address:}

Dr. Diogo Alberto Lopes Bader

Praça Getúlio Vargas, 55 / 10

Cascavel, PR, 85801-220, Brazil

E-mail: diogobader@hotmail.com 